\title{
Antioxidant Activity and Lipase Inhibitory Activity in Rice Miso Supplementary with Black Soybean, Buckwheat and Adzuki Bean
}

\author{
Chengyu Jiang ${ }^{1,2}$, Zhaohong $\mathrm{Ci}^{1,2}$, Michiyuki Kojima ${ }^{1,2, *}$ \\ ${ }^{1}$ Department of Food Science, Obihiro University of Agriculture and Veterinary Medicine, 080-8555, \\ 11, Nishi-2-Sen, Inada-Cho, Obihiro, Hokkaido, Japan \\ ${ }^{2}$ Department of Bioresources Science, United Graduate School of Agricultural Sciences, \\ Iwate University, 020-8550, 3-18-8, Ueda, Morioka, Iwate, Japan \\ *Corresponding author: kojima@obihiro.ac.jp
}

Received November 12, 2018; Revised December 12, 2018; Accepted January 10, 2019

\begin{abstract}
In the present study, we manufactured rice miso supplementary with black soybean, buckwheat and adzuki bean. We analyzed DPPH radical scavenging activity, melanoidin, peptide, reducing sugar content, and lipase inhibitory activity in various rice miso products at different fermentation periods (3, 6, 24, 36 months), respectively. DPPH radical scavenging activity, melanoidin content and lipase inhibitory activity in various rice miso products increased with prolonging the fermentation period. We found positive relationships between melanoidin content and DPPH radical scavenging activity, and lipase inhibitory activity. The correlation coefficients were more than 0.75 , respectively. Rice miso supplementary with black soybean (RM-BS), rice miso supplementary with buckwheat (RM-BW) and rice miso supplementary with adzuki bean (RM-AB) exhibited significant higher DPPH radical scavenging activity, melanoidin and lipase inhibitory activity than RM (rice miso; control), respectively. We considered that due to prolonging the fermentation period, more and more starch and protein contained in RM-BS, RM-BW and RM-AB were decomposed into reducing sugar, peptide and amino acid, than those of RM. So thus rice miso supplementary with black soybean, buckwheat and adzuki bean could improve DPPH radical scavenging activity and lipase inhibitory activity of traditional rice miso products, which may be because of plenty of melanoidin was produced through the amino acid-glucose reactions. These results would utilize in the research on development functionality of rice miso products.
\end{abstract}

Keywords: rice miso, black soybean, buckwheat, adzuki bean, melanoidin, DPPH radical scavenging activity, lipase inhibitory activity

Cite This Article: Chengyu Jiang, Zhaohong Ci, and Michiyuki Kojima, "Antioxidant Activity and Lipase Inhibitory Activity in Rice Miso Supplementary with Black Soybean, Buckwheat and Adzuki Bean.” American Journal of Food Science and Technology, vol. 7, no. 1 (2019): 7-12. doi: 10.12691/ajfst-7-1-2.

\section{Introduction}

In recent years, dietary life is characterized by a high intake of calorie and fat [1] and low intake of fruits and vegetables [2]. These unhealthy dietary habits are at high risk of developing a range of physical health conditions, such as obesity, cancer, metabolic syndrome and diabetes $[3,4,5,6]$. In Japan, the National Health and Nutrition Survey of the Ministry of Health, Labour, and Welfare indicated that there is a tendency to increase the proportion of obese patients in recent years [7].

Rice miso is a kind of Japanese traditional seasoning, which contained abundant protein, vitamins and minerals. Rice miso is usually manufactured by fermentation of boiled soybean, salt and rice-malt. It is reported that rice miso had physiological effects, including lipid peroxidation inhibition, anti-cancer and anti-diabetic $[8,9,10,11]$.
Black soybean is noted that contained a large amount of dietary fiber and anthocyanin. Several studies have found that black soybean has various physiological effects such as strong antioxidant activity, glycolysis-inhibitory activity, anti-obesity, anti-cancer and hepato-protective effect [12,13,14,15].

Buckwheat is one of the most important functional foods throughout the world [16]. It is not only an important source of basic nutrition, but also provide other positive health benefits. Buckwheat has a high level of antioxidant activity compared to other cereal crops, and this has been attributed to its high levels of flavonoid compounds [17]. It has been described that the consumption of buckwheat and buckwheat-enriched products could increase LDL peroxidation inhibitory, anti-oxidant activity and immunomodulatory activity $[18,19]$.

Adzuki bean is cultivated throughout east Asia and used in food additives, such as rice cake, bread, soup, and other snacks due to a sweet taste. It is also known 
for health-promoting and nutritional properties, such as antioxidant, renal cortex protective, anti-obesity, anti-hypotensive, and hepato-protective effects [20,21,22].

Here we fermented rice miso products supplementary with black soybean (RM-BS), buckwheat (RM-BW) and adzuki bean (RM-AB) to development and utilization of Japanese traditional rice miso, and clarify the antioxidant activity and lipase inhibitory activity in rice miso supplementary with black soybean, buckwheat and adzuki bean at different fermentation periods.

\section{Materials and Methods}

\subsection{Materials}

For the experiment, we purchased black soybean (Glycine max), buckwheat (Fagopyrum esculentum), adzuki bean (Vigna angularis), soybean (Glycine max), rice-malt, salt, seed miso from supermarket. Rice-malt was purchased from the Salt Industry Center (Japan). The rice miso products were manufactured by the method for industrial producing rice miso [23], and sampled for analysis at 3, 6, 24, 36 Months of fermentation.

DPPH (2, 2-diphenyl-1-picrylhydrazyl) was purchased from Tokyo Chemical Industry Co., Ltd. (Tokyo, Japan). Trolox, and DNS (3,5-dinitrosalicylic acid) were purchased from Sigma-Aldrich Co., LLC. (Tokyo, Japan). Glucose and glycine were purchased from Kanto Chemical Co., Inc. (Tokyo, Japan). The other reagents were purchased from Wako Pure Chemical Industries, Ltd. (Osaka, Japan).

\subsection{Extraction and Fractionation}

The extraction of miso products was extracted by the method of Saito [13]. Each miso sample (5 g) was added with $20 \mathrm{~mL}$ of $80 \% \mathrm{v} / \mathrm{v}$ ethanol and $70 \% \mathrm{v} / \mathrm{v}$ acetone, vortexed, and ultrasonicated for $30 \mathrm{~min}$. The suspension was then centrifuged at $1,006 \times \mathrm{g}$ for $10 \mathrm{~min}$. After that, according to the Ikeda's method [24]. Briefly, the mixture extract was concentrated and dissolved by $20 \mathrm{~mL}$ distilled water. Then, added by n-hexane and ethyl acetate to delaminate the solution. Subsequently, a part of water-soluble fraction was purified by chromatography through Diaion HP-20 column. The column was washed by distilled water and then eluted by methanol, and the methanol fractions were collected for chemical analysis.

\subsection{DPPH Radical Scavenging Activity Assay}

The DPPH radical scavenging activity was determined by the method of Brand-Williams [22]. The extract $(50 \mu \mathrm{L})$ was added to a microplate and mixed with $100 \mu \mathrm{L}$ of $99.5 \% \mathrm{v} / \mathrm{v}$ ethanol and $150 \mu \mathrm{L}$ DPPH solution. The solution was kept in the dark for 15 min after which its absorbance was determined at $520 \mathrm{~nm}$ by a microplate reader. Ten-fold diluted $2 \mathrm{mM}$ trolox was used as the standard and the results were expressed as $\mu$ mol trolox equivalents (TE) per gram DW miso $(\mathrm{y}=-54.07 \mathrm{x}+$ 116.96, $\left.\mathrm{R}^{2}=0.9994\right)$.

\subsection{Melanoidin Content Determination}

The content of melanoidin was determined by the method of Martins [25]. Briefly, $0.02 \mathrm{M}$ of glucose and glycine were dissolved by $0.1 \mathrm{M}$ phosphate buffer $(\mathrm{pH}$ 6.8), and heated at $120^{\circ} \mathrm{C}$ for 2 hours. Then, the solution was placed in a dialysis membrane (14000 MWCO, UC 36-32-100; EIDIA Corporation, Japan) and dialyzed against distilled water (7 days). The dialysate was lyophilized for 48 hours, and took as melanoidin standard. The absorbance was measured at $450 \mathrm{~nm}$. The results were expressed as the mg melanoidin equivalents (ME) per gram DW miso ( $\left.y=63.855 x+0.4273, R^{2}=0.9989\right)$.

\subsection{Peptide and Reducing Sugar Content Determination}

The determination of peptides was carried out by BCA method [26]. NaOH buffer $(0.1 \mathrm{M}, \mathrm{pH} 11.25)$ contained 1 g sodium bicinchoninate, 2 g sodium carbonate, $0.95 \mathrm{~g}$ sodium tartrate and 0.16 g sodium bicarbonate. The buffer was mixed with $0.4 \% \mathrm{CuSO}_{4}$ at a ratio of $50: 1$. The samples $(100 \mu \mathrm{L})$ were mixed with $2 \mathrm{~mL}$ of the mixture, and incubated at $37^{\circ} \mathrm{C}$ for $30 \mathrm{~min}$. The absorbance was measured at $562 \mathrm{~nm}$. The albumin was taken as standard, and results were expressed as the mg albumin equivalents (AE) per gram DW miso $(\mathrm{y}=59.298 \mathrm{x}-$ $\left.0.4885, \mathrm{R}^{2}=0.9968\right)$.

The reducing sugar was determined by DNS method [13] with slight modifications. Specifically, the samples $(50 \mu \mathrm{L})$ were diluted with $950 \mu \mathrm{L}$ distilled water, and thoroughly mixed with $100 \mu \mathrm{L}$ of $2 \mathrm{~N}-\mathrm{NaOH}, 100 \mu \mathrm{L}$ of $1 \%$ DNS solution, and incubated in boiling water bath for $10 \mathrm{~min}$. Absorbance was measured at 540 nm. The results were expressed as the mg glucose equivalents (GE) per gram DW miso ( $\left.\mathrm{y}=333.92 \mathrm{x}+26.832, \mathrm{R}^{2}=0.9922\right)$.

\subsection{Lipase Inhibitory Activity Assay}

Lipase inhibitory activity was determined by the improved method of Han [27]. The substrate solution was prepared by adding $10 \mathrm{mg}$ lecithin, $80 \mathrm{mg}$ triolein, and 5 mg cholic acid to $9 \mathrm{~mL}$ of $0.1 \mathrm{M}$ TES buffer (pH 7.0) (containing $10 \mathrm{mM}$ Tris, $2.5 \mathrm{mM}$ EDTA·2Na and $25 \mathrm{mM}$ sucrose), and the mixture was sonicated. Add $240 \mu \mathrm{L}$ of sample extracts with different concentration $(0.05,0.1$, $0.2 \mathrm{~g}), 80 \mu \mathrm{L}$ lipase solution and $80 \mu \mathrm{L}$ substrate solution into a glass tube, incubate at $37^{\circ} \mathrm{C}$ for $30 \mathrm{~min}$. Then, add 2 $\mathrm{mL}$ copper reagent and $4 \mathrm{~mL}$ chloroform, stir and centrifuge at $1,006 \times \mathrm{g}$ for $5 \mathrm{~min}$. Transfer $2.4 \mathrm{~mL}$ of chloroform layer to a new glass tube and add $400 \mu \mathrm{L}$ of 0.1\% DDTC-butanol solution and measure the absorbance at $440 \mathrm{~nm}$. Standard curves were using linoleic acid, and expressed as lipase inhibitory activity (\%).

Lipase inhibitory activity $(\%)=\left[1-\left(\frac{\text { Asample }}{\text { Acontrol }}\right)\right] \times 100 \%$

where $A_{\text {sample }}$ is the absorbance of the mixture of sample, substrate solution, enzyme and DDTC-butanol solvent; $A_{\text {control }}$ is the absorbance of the mixture of buffer (instead of sample), substrate solution, enzyme and DDTCbutanol solvent. 


\subsection{Statistical Analysis}

The experiments were repeated at least three times. Data were expressed as means \pm standard deviation. Significant differences were determined by one-way ANOVA and Fisher's test (SAS v. 7.1, SAS Institute Inc., Cary, NC, USA). Differences were considered to be significant at $P<0.05$.

\section{Results and Discussion}

\subsection{DPPH Radical Scavenging Activity in Rice Miso Products}

The results of DPPH radical scavenging activity of various rice miso products showed in Table $1 . \mathrm{DPPH}$ radical scavenging activity was increasing with prolonging the fermentation period of all rice miso products. 36 Months fermentation of RM-BS exhibited the highest DPPH radical scavenging activity, and the value was $6.9 \mu \mathrm{mol} / \mathrm{g} \mathrm{DW}$ miso. Comparing with 3 Months fermentation $(1.0 \mu \mathrm{mol} / \mathrm{g}$ DW miso), DPPH radical scavenging activity at 36 Months fermentation of RM-BS was increased by 6.9 folds. 36 Months fermentation of RM-BW also exhibited the highest DPPH radical scavenging activity, and the value was $6.6 \mu \mathrm{mol} / \mathrm{g} \mathrm{DW}$ miso, which increased by 7.3 folds as comparing with 3 Months fermentation. The highest DPPH radical scavenging activity of $\mathrm{RM}-\mathrm{AB}$ and $\mathrm{RM}$ (rice miso; as control) showed at 24 Months fermentation, and the values were 5.7 and $6.6 \mu \mathrm{mol} / \mathrm{g} \mathrm{DW}$ miso, respectively. As compared with 3 Months fermentation, DPPH radical scavenging activity at 24 Months fermentation of RM-AB was increased by 3.2 folds, and that of RM was increased by 4.5 folds.

Moreover, RM-BS, RM-BW and RM-AB exhibited lower DPPH radical scavenging activity than RM at 24 Months fermentation, respectively. RM-BS, RM-BW and RM-AB at 3, 6 and 36 Months fermentation exhibited significant higher $\mathrm{DPPH}$ radical scavenging activity than those of RM, respectively. RM supplementary with black soybean, adzuki bean and buckwheat produced more antioxidants than RM.

Table 1. DPPH Radical Scavenging Activity in Rice Miso Products with Different Fermentation Period

\begin{tabular}{ccccc}
\hline \multirow{2}{*}{ Periods } & \multicolumn{4}{c}{ DPPH radical scavenging activity $(\mu \mathrm{mol} / \mathrm{g}$ DW miso $)$} \\
\cline { 2 - 5 } & RM-BS & RM-BW & RM-AB & RM \\
\hline $3 \mathrm{M}$ & $1.0 \pm 0.1 \mathrm{Bd}$ & $0.9 \pm 0.1 \mathrm{Cd}$ & $1.8 \pm 0.1 \mathrm{Ad}$ & $0.9 \pm 0.1 \mathrm{Cd}$ \\
$6 \mathrm{M}$ & $4.0 \pm 0.1 \mathrm{Ac}$ & $2.6 \pm 0.1 \mathrm{Cc}$ & $3.0 \pm 0.1 \mathrm{Bc}$ & $2.9 \pm 0.1 \mathrm{Bc}$ \\
$24 \mathrm{M}$ & $6.0 \pm 0.1 \mathrm{Bb}$ & $6.1 \pm 0.1 \mathrm{Bb}$ & $5.7 \pm 0.1 \mathrm{Ca}$ & $6.6 \pm 0.1 \mathrm{Aa}$ \\
$36 \mathrm{M}$ & $6.9 \pm 0.1 \mathrm{Aa}$ & $6.6 \pm 0.1 \mathrm{Ba}$ & $5.3 \pm 0.1 \mathrm{Cb}$ & $5.4 \pm 0.1 \mathrm{Cb}$ \\
\hline
\end{tabular}

Abbreviations: M, month; DW, dry weight; RM-BS, rice miso supplementary with black soybean; RM-BW, rice miso supplementary with buckwheat; $\mathrm{RM}-\mathrm{AB}$, rice miso supplementary with adzuki bean; $\mathrm{RM}$, rice miso. Data represent the mean \pm SD from at least three independent studies. Values within a row followed by different capital letters and values within a column followed by different small letters are significant at $p<0.05$.

\subsection{Melanoidin, Peptide and Reducing Sugar Content in Rice Miso Products}

The results of melnoidin content in various rice miso products showed in Table 2. Melanoidin content was increasing with prolonging the fermentation of rice miso products. The increase trend of melanoidin content in various rice miso products was similar as DPPH radical scavenging activity. The highest melanoidin content of RM-BS showed at 36 Months fermentation $(19.9 \mathrm{mg} / \mathrm{g}$ DW miso), which was increased by 6.4 folds, as compared with 3 Months fermentation (3.1 mg/g DW miso). As compared with RM-BW of 3 Months fermentation, melanoidin content of 36 Months fermentation $(12.7 \mathrm{mg} / \mathrm{g}$ DW miso) increased by 6.1 folds. The highest melanoidin content of RM-AB and RM showed at 24 Months fermentation (10.6 mg/g DW miso; $11.6 \mathrm{mg} / \mathrm{g} \mathrm{DW}$ miso), and increased by 4.2 folds and 4.5 folds, respectively, as compare with 3 Months fermentation. Moreover, there was high positive relationship between melanoidin content and DPPH radical scavenging activity (Figure 1). The antioxidant activity of decocted Zhenjiang Aromatic Vinegar was increasing along with the increased of melanoidin content [28].

Table 2. Melanoidin Content in Rice Miso Products with Different Fermentation Period

\begin{tabular}{crrrr}
\hline \multirow{2}{*}{ Periodss } & \multicolumn{4}{c}{ Melanoidin content (mg/g DW miso) } \\
\cline { 2 - 5 } & \multicolumn{1}{c}{ RM-BS } & \multicolumn{1}{c}{ RM-BW } & \multicolumn{1}{c}{ RM-AB } & \multicolumn{1}{c}{ RM } \\
\hline $3 \mathrm{M}$ & $3.1 \pm 0.1 \mathrm{Ad}$ & $2.1 \pm 0.1 \mathrm{Cc}$ & $2.5 \pm 0.1 \mathrm{Bc}$ & $2.6 \pm 0.1 \mathrm{Bd}$ \\
$6 \mathrm{M}$ & $11.4 \pm 0.5 \mathrm{Ac}$ & $5.2 \pm 0.2 \mathrm{Db}$ & $6.5 \pm 0.1 \mathrm{Cb}$ & $8.0 \pm 0.1 \mathrm{Bc}$ \\
$24 \mathrm{M}$ & $15.6 \pm 0.3 \mathrm{Ab}$ & $12.7 \pm 0.1 \mathrm{Ba}$ & $10.6 \pm 0.4 \mathrm{Da}$ & $11.6 \pm 0.2 \mathrm{Ca}$ \\
$36 \mathrm{M}$ & $19.9 \pm 0.8 \mathrm{Aa}$ & $12.7 \pm 0.6 \mathrm{Ba}$ & $10.5 \pm 0.4 \mathrm{Ca}$ & $10.7 \pm 0.1 \mathrm{Cb}$ \\
\hline
\end{tabular}

Abbreviations: M, month; DW, dry weight; RM-BS, rice miso supplementary with black soybean; RM-BW, rice miso supplementary with buckwheat; $\mathrm{RM}-\mathrm{AB}$, rice miso supplementary with adzuki bean; $\mathrm{RM}$, rice miso. Data represent the mean \pm SD from at least three independent studies. Values within a row followed by different capital letters and values within a column followed by different small letters are significant at $p<0.05$.

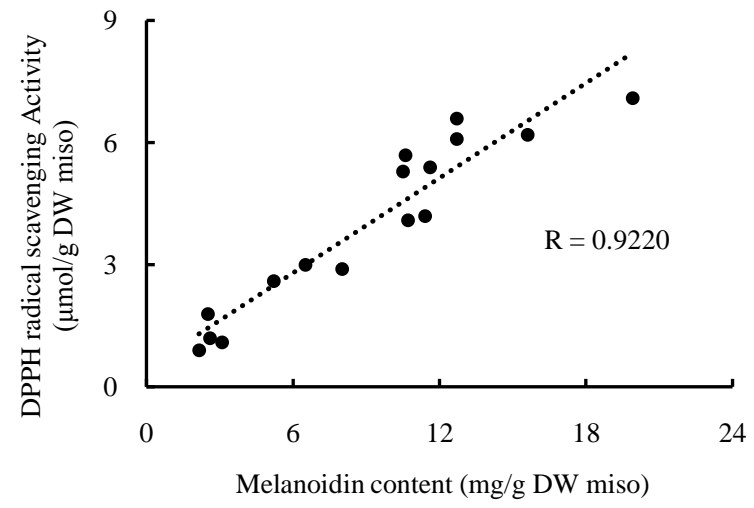

Figure 1. Relationship between DPPH radical scavenging activity and melanoidin in rice miso products with different fermentation period.

Peptide and reducing sugar content in various rice miso products showed in Table 3 and Table 4 . The fermentation process could cause starch and protein contained in rice miso to decompose into reducing sugar, peptide and amino acid by Aspergillus oryzae [24,29,30]. At the early fermentation period ( 3 and 6 Months fermentation) of various rice miso products, the peptide and reducing sugar increased. However, the peptide and reducing sugar content declined obviously from 6 Months fermentation. We speculated that plenty of melanoidin produced through the amino acid-glucose reaction from 6 Months fermentation of various rice miso products, and the 
peptide and reducing sugar content declined from fermentation after 6 months. To compare with RM, the ratios of peptide content contained in RM-BS, RM-BW and RM-AB increased from 0.6 to 1.4 folds with prolong fermentation period, and the ratios of reducing sugar increased from 0.7 to 2.5 folds. Buckwheat and black soybean are mainly rich in their protein content, and adzuki bean (Vigna angularis) contains more starch than soybeans [31,32]. Therefore, we speculated that due to
RM-BS, RM-BW and RM-AB have more peptide and reducing sugar than RM, more melanoidins produced, which had antioxidant activity. Moreover, the composition of melanoidin produced from an amino acid-sugar model system also effects the strength of antioxidant activity [33]. The high molecular weight reaction products resulting from the interaction of lysine with hexanal showed a higher radical scavenging activity than glycine/glucose model [34].

Table 3. Peptide Content in Rice Miso Products with Different Fermentation Period.

\begin{tabular}{ccrrr}
\hline \multirow{2}{*}{ Periods } & \multicolumn{4}{c}{ Peptide content $(\mathrm{mg} / \mathrm{g}$ DW miso) } \\
\cline { 2 - 5 } & \multicolumn{1}{c}{ RM-BS } & \multicolumn{1}{c}{ RM-BW } & RM-AB & RM \\
\hline $3 \mathrm{M}$ & $86.6 \pm 2.7 \mathrm{Cd}$ & $99.8 \pm 2.2 \mathrm{Bd}$ & $97.7 \pm 2.5 \mathrm{Bd}$ & $118.4 \pm 4.3 \mathrm{Ab}$ \\
$6 \mathrm{M}$ & $188.7 \pm 8.3 \mathrm{Aa}$ & $171.1 \pm 0.5 \mathrm{Ca}$ & $155.2 \pm 2.5 \mathrm{Da}$ & $177.1 \pm 6.3 \mathrm{Ba}$ \\
$24 \mathrm{M}$ & $130.5 \pm 6.5 \mathrm{Bb}$ & $140.8 \pm 0.6 \mathrm{Ab}$ & $109.3 \pm 2.4 \mathrm{Cb}$ & $96.8 \pm 2.3 \mathrm{Dc}$ \\
$36 \mathrm{M}$ & $101.7 \pm 2.3 \mathrm{Cc}$ & $127.1 \pm 0.5 \mathrm{Ac}$ & $105.2 \pm 1.6 \mathrm{Bc}$ & $93.8 \pm 2.0 \mathrm{Dd}$ \\
\hline
\end{tabular}

Abbreviations: M, month; DW, dry weight; RM-BS, rice miso supplementary with black soybean; RM-BW, rice miso supplementary with buckwheat; $\mathrm{RM}-\mathrm{AB}$, rice miso supplementary with adzuki bean; RM, rice miso. Data represent the mean \pm SD from at least three independent studies. Values within a row followed by different capital letters and values within a column followed by different small letters are significant at $p<0.05$.

Table 4. Reducing Sugar Content in Rice Miso Products with Different Fermentation Period.

\begin{tabular}{ccccc}
\hline \multirow{2}{*}{ Periods } & \multicolumn{4}{c}{ Reducing sugar content (mg/g DW miso) } \\
\cline { 2 - 5 } & RM-BS & RM-BW & RM-AB & RM \\
\hline $3 \mathrm{M}$ & $389.7 \pm 1.5 \mathrm{Ab}$ & $274.7 \pm 2.2 \mathrm{Cb}$ & $260.3 \pm 0.8 \mathrm{Db}$ & $289.1 \pm 2.3 \mathrm{Bb}$ \\
$6 \mathrm{M}$ & $443.3 \pm 5.3 \mathrm{Aa}$ & $354.8 \pm 6.4 \mathrm{Ba}$ & $317.0 \pm 4.8 \mathrm{Da}$ & $349.2 \pm 8.7 \mathrm{Ca}$ \\
$24 \mathrm{M}$ & $146.3 \pm 0.7 \mathrm{Bc}$ & $201.1 \pm 2.3 \mathrm{Ac}$ & $132.0 \pm 0.8 \mathrm{Cc}$ & $93.6 \pm 3.2 \mathrm{Dc}$ \\
$36 \mathrm{M}$ & $125.8 \pm 0.5 \mathrm{Bd}$ & $142.0 \pm 0.8 \mathrm{Ad}$ & $121.8 \pm 0.7 \mathrm{Cd}$ & $79.9 \pm 2.2 \mathrm{Dd}$ \\
\hline
\end{tabular}

Abbreviations: M, month; DW, dry weight; RM-BS, rice miso supplementary with black soybean; RM-BW, rice miso supplementary with buckwheat; $\mathrm{RM}-\mathrm{AB}$, rice miso supplementary with adzuki bean; RM, rice miso. Data represent the mean \pm SD from at least three independent studies. Values within a row followed by different capital letters and values within a column followed by different small letters are significant at $p<0.05$.
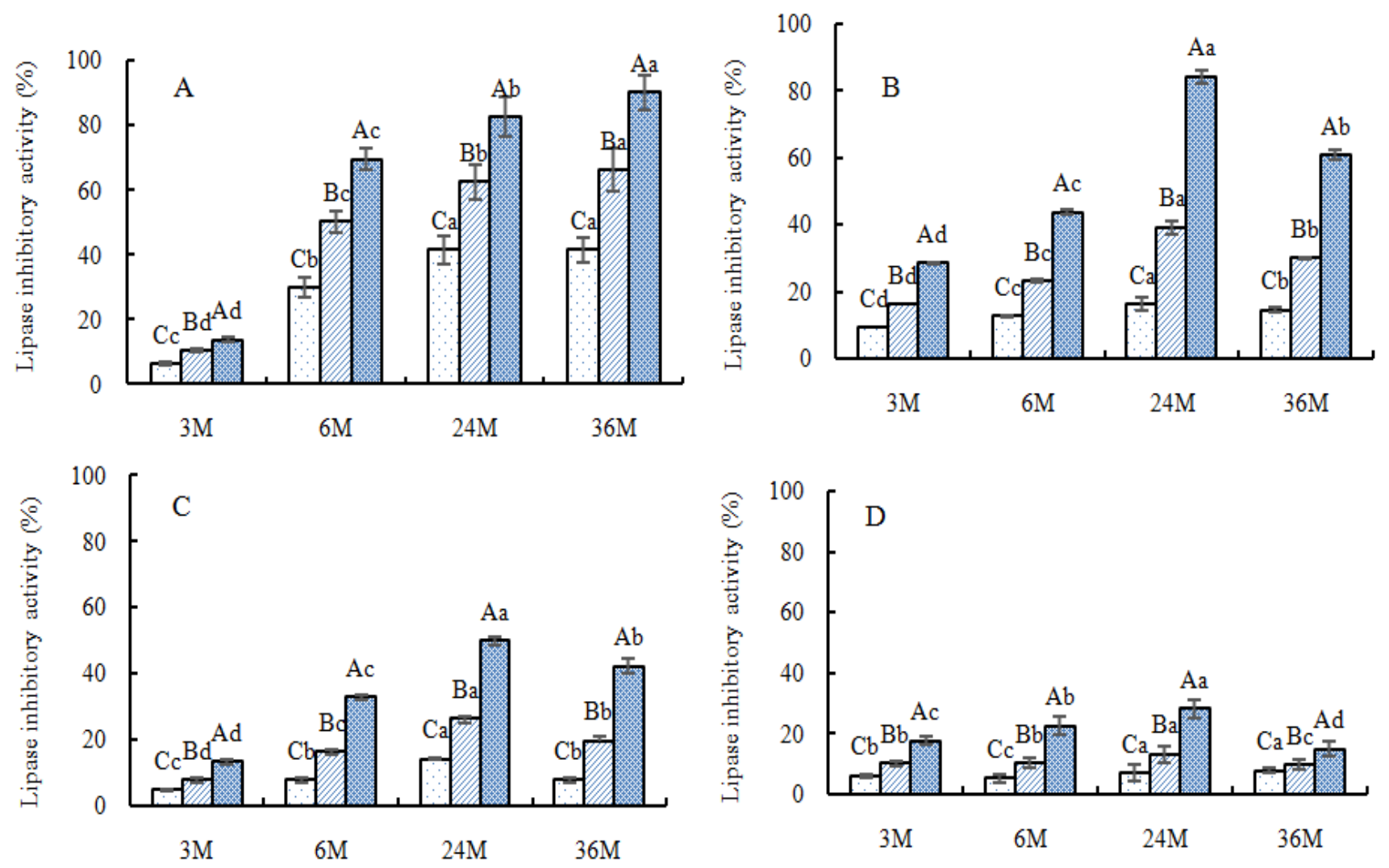

Figure 2. Lipase inhibitory activity contained in different weights of rice miso products with different fermentation period. A, RM-BS. B, RM-BW. C, RM-AB. D, RM. $\square$ for the $0.05 \mathrm{~g}$ DW miso; 0 for the $0.1 \mathrm{~g}$ DW miso; ; for the $0.2 \mathrm{~g}$ DW miso. Values within a column followed by different capital letters and values within a row followed by different small letters are significant at $p<0.05$. 


\subsection{Lipase Inhibitory Activity in Rice Miso Products}

Lipase inhibitory activity in various rice miso products at different concentrations showed in Figure 2. Lipase inhibitory activity in various rice miso products increased significantly with prolonging fermentation period. The strongest lipase inhibitory activity in RM-BS was at 36 Months fermentation and RM-BW, RM-AB and RM was at 24 Months fermentation. Lipase inhibitory activity of RM-BS, RM-BW and RM-AB were also significant higher than RM (rice miso; as control) at different fermentation period, respectively. Moreover, we found positive relationships between melanoidin content and lipase inhibitory activity at the concentrations of $0.05,0.1$, $0.2 \mathrm{~g}$ rice miso products, the correlation coefficients were $0.7518,0.7883$ and 0.8016 , respectively. Therefore, we concluded that supplementing with black soybean, buckwheat and adzuki bean could improve lipase inhibitory activity of traditional rice miso products. Doenjang intake resulted in significant reduction of body weight gain in high fat-fed mice [35], and HFD-fed rats drinking coffee or melanoidin had an effect of reduced fat [36].

\section{Conclusion}

In the present study, DPPH radical scavenging activity, lipase inhibitory activity and melanoidin content in various rice miso products increased with prolonging fermentation periods, and RM-BS, RM-BW and RM-AB were significant higher than those of $R M$, respectively. We found positive relationships between melanoidin content and DPPH radical scavenging activity, and lipase inhibitory activity, respectively. Due to prolonging the fermentation period, more and more starch and protein contained in RM-BS, RM-BW and RM-AB to decompose into reducing sugar, peptide and amino acid than those of $\mathrm{RM}$. So thus we concluded that traditional rice miso supplementary with black soybean, buckwheat and adzuki bean could improve DPPH radical scavenging activity and lipase inhibitory activity of traditional rice miso products, which were because of plenty of melanoidin was produced through the amino acid-glucose reactions.

These observations also might provide important information for further research on developing health benefits of rice miso products.

\section{Acknowledgments}

We acknowledge the financial support given by the Obihiro University of Agriculture and Veterinary Medicine, as well as Iwate University, for the completion of the study.

\section{Statement of Competing Interests}

The authors have no competing interests.

\section{List of Abbreviations}

M: month; RM: rice miso; RM-BS: rice miso supplementary with black soybean; RM-BW: rice miso supplementary with buckwheat; RM-AB: rice miso supplementary with adzuki bean; DW: dry weight; TE: trolox equivalents; DPPH: 2,2-diphenyl-1-picrylhydrazyl; ME: melanoidin equivalents; BCA: bicinchoninic acid; AE: albumin equivalents; GE: glucose equivalents; DNS: 3,5-dinitrosalicylic acid; DDTC: sodium diethyldithiocarbamic acid; Tris: tris(hydroxymethyl)aminomethane; EDTA-2Na: ethylenediaminetetraacetic acid disodium salt, 2-hydrate.

\section{References}

[1] Stokes, C., Peet, M., "Dietary sugar and polyunsaturated fatty acid consumption as predictors of severity of schizophrenia symptoms," Nutritional Neuroscience, 7(4). 247-249. Aug 2004.

[2] McCreadie, R.G., "Diet, smoking and cardiovascular risk in people with schizophrenia: descriptive study,” British Journal of Psychiatry, 183. 534-539. Dec 2003.

[3] Cimo, A., Stergiopoulos, E., Cheng, C., Bonato, S., Dewa, C.S., "Effective lifestyle interventions to improve type II diabetes self-management for those with schizophrenia or schizoaffective disorder: a systematic review,” BMC Psychiatry, 12: 24. Mar 2012.

[4] Correll, C.U., "Prevalence, incidence and mortality from cardiovascular disease in patients with pooled and specific severe mental illness: a large-scale meta-analysis of 3,211,768 patients and 113,383,368 controls,” World Psychiatry, 16(2). 163-180. Jun 2017.

[5] Crump, C., Winkleby, M. A., Sundquist, K., Sundquist. J., "Comorbidities and mortality in persons with schizophrenia: A Swedish national cohort study,” American Journal of Psychiatry, 170. 324-333. Mar 2013.

[6] Sundström, J., Risérus, U., Byberg, L., Zethelius, B., Lithell, H., Lind, L., "Clinical value of the metabolic syndrome for long term prediction of total and cardiovascular mortality: prospective, population based cohort study,” British Medical Journal, 332. 878-882. Apr 2006.

[7] Results of Heisei 28 "National Health and Nutrition Survey," [The situation on the physique and lifestyle habits still has regional difference], https://www.mhlw.go.jp/stf/houdou/0000177189.html Sep 2017. [Online]

[8] Kwon, D.Y., Daily, J.W., Kim, H.J., \& Park, S., "Antidiabetic effects of fermented soybean products on type 2 diabetes," Nutrition Research, 30(1). 1-13. Jan 2010.

[9] Santiago, L.A., Hiramatsu, M., and Mori, A., "Japanese soybean paste miso scavenges free radicals and inhibits lipid peroxidation," Journal of Nutritional Science and Vitaminology, 38(3). 297-304. Jul 1992.

[10] Watanabe, H., "Biological efficacies of Miso," Journal of the Brewing Society of Japan, 105(11). 714-723. Nov 2010.

[11] Ito, A., Gotoh, T., \& Fujimoto, N., "Chemoprevention of cancers by miso and isoflavones,” Journal of Toxicologic Pathology, 11(2). 79-84. Jun 1998.

[12] Yoshikawa, H., Kuwashima, C., Kotaru, M., " $\alpha$-amylase inhibitors in the seeds of the genus Phaseolus and their characteristics," Research bulletin of Kyoto Koka Women's University, 47. 227-237. Dec 2009.

[13] Saito, Y., Nishi, S., Koaze, H., Hironaka, K., and Kojima, M., "Antioxidant and Inhibitory Activity on $\alpha$-Amylase and $\alpha$ Glucosidase in Legume Polyphenols,” Journal of the Japanese Society for Food Science and Technology, 54(12). 563-567. Jan 2007.

[14] Acquaviva, R., Russo, A., Galvano, F., Galvano, G., Barcellona, M.L., Li Volti, G., and Vanella, A., "Cyanidin and cyanidin 3-O$\beta$-D-glucoside as DNA cleavage protectors and antioxidants,” Cell Biology and Toxicology, 19(4). 243-252. Aug 2003. 
[15] Lin, W.H., Yang, H.W., Hsu, C.K., Jhan, H.K., Lo, D.Y., "Black Soybean Shows Protective Function against Carbon Tetrachlorideinduced Liver Damage in Sprague-dawely Rats," Journal of Botanical Sciences, 5(1). 7-15. Dec 2016.

[16] Lee, L.S., Choi, E.J., Kim, C.H., Sung, J.M., Kim, Y.B., Seo, D.H., Choi, H.W., Choi, Y.S., Kum, J.S., Park, J.D., "Contribution of flavonoids to the antioxidant properties of common and tartary buckwheat,” Journal of Cereal Science, 68. 181-186. Mar 2016.

[17] Holasova, M., Fiedlerova, V., Smrcinova, H., Orsak, M., Lachman, J., Vavreinova. S., "Buckwheat - the source of antioxidant activity in functional foods," Food Research International, 35. 207-211. Dec 2002.

[18] Jiang, P., Burczynski, F., Campbell, C., Pierce, G., Austria, A., Briggs, C.J., "Rutin and flavonoid contents in three buckwheat species Fagopyrum esculentum, F. tataricum, and F. homotropicum and their protective effects against lipid peroxidation," Food Research International, 40(3). 356-364. Apr 2007.

[19] Oh, M.J., Choi, H.D., Ha, S.K., Choi, I., Park, H.Y., "Immunomodulatory effects of polysaccharide fraction isolated from Fagopyrum esculentum on innate immune system," Biochemical and Biophysical Research Communications, 496(4). 1210-1216. Feb 2018.

[20] Durak, A., Baraniak, B., Jakubczyk, A., Świeca. M., "Biologically active peptides obtained by enzymatic hydrolysis of Adzuki bean seeds,” Food Chemistry, 141(3). 2177-2183. Dec 2013.

[21] Kojima, M., Yamashita, S., Nishi, S., Saito, Y., and Maeda, R., "Anti-oxidative effect and Liver Protective Action of Adzuki Polyphenol," Journal of the Japanese Society for Food Science and Technology, 53(7). 386-392. Jul 2006.

[22] Kojima, M., Nishi, S., Yamashita, S., Saito, Y., and Maeda, R. "Smaller Increase in Serum Cholesterol Level in Rats Fed an Ethanol Extract of Adzuki Bean Seeds,” Journal of the Japanese Society for Food Science and Technology, 53(7). 380-385. Jul 2006.

[23] Jiang, C.Y., Ci, Z.H., Kojima, M., "Antioxidant Activity, $\alpha$ Glucosidase and Lipase Inhibitory Activity in Rice Miso with Kidney Bean,” Journal of Food and Nutrition Research, 6(8). 504-508. Aug 2018.

[24] Ikeda, R., Ohta, N., \& Watanabe, T., "Changes of Isoflavones at Various Stages of Fermentation in Defatted Soybeans," Journal of the Japanese Society for Food Science and Technology, 42(5). 322-327. May 1995.

[25] Martins, S.I.F.S., Van Boeke, M.A.J.S., "Melanoidins extinctioin coefficient in the glucose/glycine Maillard reaction," Food Chemistry 83(1). 135-142. Oct 2003.
[26] Olson B, Markwell J., “Assays for determination of protein concentration,” Current Protocols in Protein Science, Unit 3.4.16, May 2007.

[27] Han, L.K., Gong, X.J., Kawano, S., Saito, M., Kimura, Y., Okuda, H., "Antiobesity Actions of Zingiber officinale Roscoe," Journal of the Pharmaceutical Society of Japan, 125(2). 213-217. Feb 2005.

[28] Liu, J.Y., Gan, J., Yu, Y.J., Zhu, S.H, Yin, L.J., Cheng, Y.Q., "Effect of laboratory-scale decoction on the antioxidative activity of Zhenjiang Aromatic Vinegar: The contribution of melanoidins," Journal of Functional Foods, 21. 75-86, Mar 2016.

[29] Yamagata Y., "Proteolytic Enzymes of A. oryzae,” Kagaku to Seibutsu, 54(2). 109-116. Jan 2016.

[30] Yoshioka K, Suzuki Y, Morikawa K., "Changes in Saccharide Contents and Color of Homemade Rice Miso during Fermentation," Bulletin of Osaka Prefectural College of Health Sciences, 3. 57-62, Dec 1997.

[31] Motta, C., Castanheira, I., Gonzales, G.B., Delgado, I., Torres, D., Santos, M., Matos, A.S., "Impact of cooking methods and malting on amino acids content in amaranth, buckwheat and quinoa," Journal of Food Composition and Analysis, Available online. Nov 2018. (In press)

[32] Kan, L.J., Nie, S.P., Hu, J.L., Wang, S.N., Bai, Z.Y., Wang, J.Q. Zhou, Y.M., Jiang, J., Zeng, Q., Song, K., "Comparative study on the chemical composition, anthocyanins, tocopherolsand carotenoids of selected legumes," Food Chemistry, 260(1). 317-326. Sep 2018.

[33] Kim, J.S., \& Lee, Y.S., “Antioxidant activity of Maillard reaction products derived from aqueous glucose/glycine, diglycine, and triglycine model systems as a function of heating time," Food Chemistry, 116(1). 227-232. Sep 2009.

[34] Adams, A., Kitrytė, V., Venskutonis, R., \& De Kimpe, N., "Impact of lipid oxidation-derived aldehydes and ascorbic acid on the antioxidant activity of model melanoidins," Food Chemistry, 135(3). 1273-1283. Dec 2012.

[35] Park, N.Y., Rico, C.W., Lee, S.C., Kang, M.Y., "Comparative effects of doenjang prepared from soybean and brown rice on the body weight and lipid metabolism in high fat-fed mice," Journal of Clinical Biochemistry and Nutrition, 51(3). 235-240. Nov 2012.

[36] Park, N.Y., Rico, C.W., Lee, S.C., Kang, M.Y., “Coffee Reduces Liver Damage in a Rat Model of Steatohepatitis: The Underlying Mechanisms and the Role of Polyphenols and Melanoidins," Hepatology, 52(5). 1652-1661. Nov 2010. 